\title{
Limitations and Usage of E-commerce in Developing Countries
}

\author{
Muneer Abbad \\ Community College of Qatar, Doha, 222 Qatar
}

\begin{abstract}
Information and communication technologies (ICT) and Internet have deep effect on the communications between companies and customers. Traditional trade transactions don't remain the main way of communications between them. Many companies have tried to introduce electronic ways to deal with customers. E-commerce is one of the channels that used by a lot of companies to reach and interact with customers. Many studies in e-commerce have been conducted in developed countries. Therefore, this study attempts to contribute by focusing on e-commerce in one of developing countries, Jordan. Traditional way of communications and conducting transactions between companies in Jordan and customers is the most widespread method. Many companies in Jordan have tried to introduce e-commerce channel to reduce the transactions in the traditional way, to gain from the befits of e-commerce, and to reduce the costs. Despite all their efforts aimed at introducing the new way of transactions, this way remained largely unnoticed by the customers. The main aim of this study is to focus on the main limitations that could affect the usage rate of e-commerce in Jordan.
\end{abstract}

Keywords: Adoption, Developing Countries, E-commerce, Usage.

\section{Introduction}

HE World Wide Web (WWW) and Internet have been introducing new and modern ways of communications between the companies and customers all over the world. Companies take these ways as an opportunity to conduct their business for commercial purposes. E-commerce as one of Internet applications was used in all over the world. "Ref [1]" stated that "to improve profits and achieve strategic sustainability in a rapidly changing competitive environment, many Websites have been repackaging themselves by targeting new markets, expanding into the offline world, forming alliances, licensing software, and adjusting their core offering to focus on the most profitable products and customers". As developed countries, developing countries should use this opportunity to get the benefits of e-commerce. "Ref [2] stated that developing countries have to catch up with the developed world by establishing the required information infrastructure to overcome the dangers of isolation and polarization". The growth path is through the development of information technology (IT) industries and greater application of IT in society. These IT industries must be compatible with local conditions and conductive to industrialization".

Jordan is recognised as a model developing country and by its success caused responsiveness from the international community. Jordan is located in the centre of the Arab World and the Middle East. Jordan also enjoys economic and political stability comparing to other neighbouring countries [3]. When it comes to Information and Communication Technologies (ICT) sector, Jordan is witnessed and still witnessing rapid developments, such developments enable Jordan to gain many benefits of the globalising world [2]. Comparing to other neighbouring countries, Jordan has good telecommunication and latest Internet services technology. Over the past decade, the growth of information technology highly affected the businesses worldwide. The United States of America is considered the leader on e-commerce [4]. On the other hand, e-commerce in Jordan is not widely used. "Ref [5]" pointed that Business-to-Business e-commerce applications in Jordan are incorporated most of transactions between few Jordanian organisations and foreign partners. On the other hand, Business-to-Consumer e-commerce is still very limited to few transactions. Because of that, this study will focus on the main limitation that face customers in using e-commerce in Jordan.

\section{Literature Review}


There is no a universally acknowledged definition for E-Commerce, and many researchers define it differently. "Ref [6]" define e-commerce as exchanging money, products, services and/or information between economic entities over the internet or any other electronic technologies. In addition, [7] defines e-commerce as all transactions that are conducted electronically between an organisation and any other party. Similarly, the UK Cabinet Office [8] also used a broad definition to define the scoop of e-commerce: "E-Commerce is the exchange of information across electronic network, at any stage in the supply chain, whether within an organisation, between businesses, between businesses and consumers, or between the public and the private sector, whether paid or unpaid". All previous definitions acknowledged the fact that e-commerce includes any business transaction between two parties whether financial transaction or non-financial transaction over any digital technology. The differences among the previous definitions relate to the parties involved in e-commerce. In a business-to-business environment, a relationship between two organisations is formed using e-commerce to achieve business transactions between them. The relationship usually focuses on Supply Chain Management (SCM). But in the Business-to-consumer environment; Business-to-Consumer; a relationship between two organisation and consumer is formed using e-commerce to achieve business transactions. It usually focuses on Customer Relationship Management (CRM).

E-commerce has many benefits for companies, customers, and society. "Ref [9]" summarized the main benefits of e-commerce as the following:

- To companies "e-commerce expands the marketplace to national and international markets. E-commerce decreases the cost of creating, processing, distributing, storing, and retrieving paper-based information. Supply chain inefficiencies can be minimized with e-commerce. It provides a competitive advantage for companies. E-commerce reduces the time between the outlay of capital and the receipt of products. Ecommerce lowers telecommunications costs. E-commerce enables efficient e-procurement. E-commerce enables companies to interact more closely with customers, even if through intermediaries".

- To customers "E-commerce allows consumers to shop or perform other transactions year around, 24 hours a day, from almost any location. E-commerce provides consumers with more choices; they can select from many vendors and from more products. E-commerce frequently provides consumers with less expensive products and services by allowing them to shop in many places and conduct quick comparisons. Ecommerce allows for quick delivery. Consumers can locate relevant and detailed product information in seconds, rather than days or weeks. E-commerce makes it possible to participate in virtual auctions. Ecommerce allows customers to interact with other customers in electronic communities and exchange ideas as well as compare experiences. E-commerce facilitates competition, with results in substantially lower prices for consumers".

- To society "Less traffic on the roads and reduced air pollution. Increase the standard of living of people. People are now able to enjoy products and services that otherwise are unavailable. This includes opportunities to learn skilled professions or earn a college degree. Public services, such as a health care, education, and distribution of government social services can be delivered at a reduced cost and/or improved quality. For example, e-commerce provides rural doctors access to information and technologies with which they can better treat their patients".).

\section{Limitations of E-Commerce}

As we have many benefits for using e-commerce, there are some limitations of using e-commerce. For example, [10] found that management support and security are the main limitations of e-commerce in travel industry. "Ref [5]" found privacy, censorship, intellectual property and credit cards are the main limitations of ecommerce.

In addition, the main limitations of using e-commerce could come from: PC penetration, IT infrastructure, economic conditions, political issues, business issues, culture, marketing issues, lack of knowledge, taxes, documentation problem, regulations, languages, trust, security and privacy issues. 
"Ref [9]" classified the limitations of e-commerce into technical and non-technical limitations:

1- Technical limitations of E-commerce: "System security, reliability, standards, and some communication protocols are still evolving. In many areas, telecommunications bandwidths are insufficient. Software development tools are still evolving and changing rapidly. It is difficult to integrate the Internet and e-commerce software with some existing applications and databases. Vendors may need special Web servers, network servers, and other infrastructure developments. Some e-commerce software might not fit with some hardware, or it may be incompatible with certain operating systems or components".

2- Non-technical limitations of e-commerce: "The cost of developing e-commerce in-house can be very high and mistakes made due to lack of experience may result in delays. Security and privacy are important in the B2C area. In many cases, customers do not trust an unknown, faceless seller, paperless transactions, and electronic money. Some customers like to touch items, such as clothes, so they know exactly what they are buying. Many legal issues are as yet unresolved, and in many circumstances government regulations and standards are not yet refined enough to deal with the intricacies of e-commerce. E-commerce does not have enough support services. In many areas there is not enough critical mass for e-commerce to be successful. In most applications, there are not yet enough sellers and buyers for profitable e-commerce operations. Some fear that as e-commerce reduces face-to-face social interactions, there could be a breakdown in human relations. Internet access is still expensive and/or inconvenient for many potential customers".

"Ref [11]" summarised the main barriers to global e-commerce: language barriers, cultural barriers, availability of personal computers, computer literacy and knowledge barriers, access charges, and government regulations.

\section{Methodology}

Quantitative and qualitative methods will be used in this study to reach to the main objectives of this study. The first phase is conducting focus interviews with three groups of students in Jordan to summarize the main limitations of using e-commerce. Then, the second phase is establishing the questionnaire that will be used to collect the required data for the analysis part. Students from different colleges and universities will be used to collect the data. The sample size will be 200 students.

Proposed Model and Hypothesis

Based on the literature review and the focus group interviews, Fig. 1 shows the main limitations of ecommerce that effect the usage of e-commerce in Jordan.

Based on the proposed model, the following hypothesis are formulated:

H1: Perceived usefulness (PU) has a positive effect on the usage of e-commerce.

$\mathrm{H} 2$ : Perceived ease of use (PEOU) has a positive effect on the usage of e-commerce.

H3: Security and trust have a positive effect on the usage of e-commerce.

H4: Internet experience has a positive effect on the usage of e-commerce.

H5: Language has a positive effect on the usage of e-commerce.

H6: Laws and regulations have a positive effect on the usage of e-commerce.

H7: Enjoyability has a positive effect on the usage of e-commerce. 


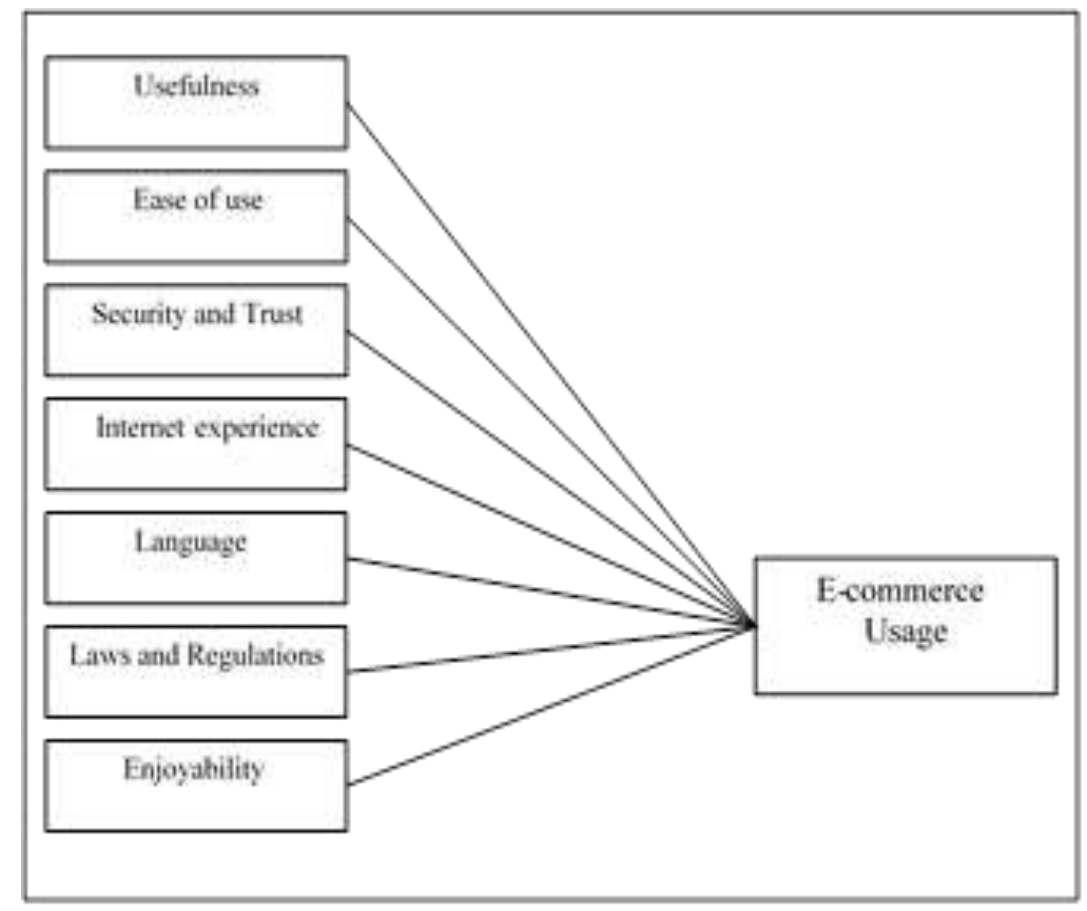

Fig. 1: Proposed Model

\section{Data Analysis Techniques}

After collecting the required data, the main statistical techniques that will be used in the analysis are:

1- Exploratory factor analysis (EFA) will be used as the initial step in identifying the latent factors in the questionnaires.

2- Confirmatory factor analysis (CFA) will be performed on the hypothesized measurement models.

3- Structural equation modelling (SEM) will be performed on the structural models to evaluate the hypothesized relationships.

4- Analysis of variances (ANOVA) will be used to determine some demographic (gender, age, and income) differences on the factors of the study.

Exploratory and confirmatory factor analysis and structural equation modelling techniques will be used here to check if we can find out mediating factors that could affect the usage of e-commerce (e.g. perceived usefulness and perceived ease of use).

\section{Conclusion}

The main aim of this study is to identify the main limitations of e-commerce in developing countries and how these limitations will affect the usage rate of e-commerce. The results of this study will give recommendations on how companies can increase the usage rate of e-commerce. The proposed model of the study was developed based on focus group interviews with university students and literature review. Then, the next step is to test the proposed model by collecting data from 200 students from different colleges and universities by using a self-administrated questionnaire. The main limitations of e-commerce are: perceived usefulness, perceived ease of use, trust and security, Internet experience, language, and enjoyability. Based on the results of this study, data will be collected and analysed in future studies. 


\section{References}

[1] A. M. Chircu and R. J. Kauffman (2000) "Limits to value in electronic commerce-related IT investments". Journal of Management Information Systems, 17(2), 59-80. https://doi.org/10.1080/07421222.2000.11045645

[2] S. Al-Jaghoub and C. Westrup (2003) "Jordan and ICT Development: Towards a Competition State", International technology and people, Vol. 16 (1), pp. 93-110. https://doi.org/10.1108/09593840310463032

[3] K. Naser (1998) "Comprehensives of disclosure of non-financial companies listed on the Amman financial market" International of Commerce and Management 2, (8) 88-119.

[4] https://doi.org/10.1108/eb047365

[5] J. Fraser, N. Fraser, and F. McDonald (2000), "The Strategic Challenge of Electronic Commerce", Supply Chain Management: An International journal., Vol. 5 (1), pp. 7-14. https://doi.org/10.1108/13598540010312936

[6] M. Sahawneh (2003) E-commerce: The Jordanian experience. The Royal Scientific Society, Amman, Jordan.

[7] Laudon and Laudon, (2017) Management information System, 7th ed., prentice Hall, New Jersey.

[8] D. Chaffey (2009) E-business and e-commerce management strategy, implementation and practice. 4th edn. New York: FT Prentice Hall

[9] Cabinet Office (1999) e-commerce@its.best.uk. London: The Performance and Innovation Unit

[10] E. Turban (2016) "Electronic Commerce 2006: A Managerial Perspective", 4th Edition (Pie) (Hardcover), Prentice Hall, USA.

[11] V. C. S. Heung (2003), "Barriers to Implementing E-commerce in the travel Industry: A practical Perspective ", International Journal of Hospitality Management, 22, pp. 111-118.

https://doi.org/10.1016/S0278-4319(02)00075-0

[12] M. Kotab and K. Helsen (2001) “Global Marketing Management”, 2nd ed., Wiley, New York. 